Final Report:

The Midwest Analytical Team for Research Instrumentation of X-Rays (MATRIX) Beamline X-18A at the National Synchrotron Light Source of Brookhaven National Laboratory

Department of Energy Grant No:

DDE-FG02-85ER45183 DOE Patent Clearance Granted
12/01/24-07/31/00 Mark P Dvorscak

\title{
Overview:
}

The Midwest Analytical Team for Research Instrumentation of X-Rays (MATRIX) beamline X-18A at the National Synchrotron Light Source (NSLS) of Brookhaven National Laboratory (BNL) was established and developed by Professor G. L. Liedl, former Head and Professor of Materials Engineering at Purdue University. During the six years of this funding the beamline facility, managed on-site by Dr. Steven Ehrlich (now at BNL employee) was very successful in the production of research on identification of transformation and transitions in materials. As this program reached the end of the project period maintaining access to this facility became an important consideration. Paul Sokol and colleagues at Penn State identified resources and a strategy that would enable continuation of this beamline with access for the team members. This should enable continued activity on this important and unique materials research facility. The new home of the beamline can be found at http://sokol.phys.psu.edu/MATRIX/.

\section{The Accomplishments of MATRIX}

MATRIX was founded to serve the common interests of a group of scientists interested in phase characterizations/transformations. The function of MATRLX is to provide and operate a high intensity X-ray synchrotron beam line to support research and to provide a forum for the exchange of information on the applications of synchrotron radiation to this area of materials research. MATRIX has been an active and evolving group at NSLS since the first photons were available. It has generated, over the years, a physical operation and an atmosphere of support to enable the optimal use of available photons for both member and general users.

The primary focus of the research effort for the MATRIX PRT is phase characterization/transformation. Our understanding of the properties/behavior of materials is most frequently correlated through our knowledge of the stat; of the materials and how it got to that state. Our ability to characterize the structural state of a material is needed to uncerstand many of the most useful properties of the material. Furthermore, insufficient understanding in the processing of materials, i.e., ability to make a material with the form and desired properties; has become one of the major barriers in our development of materials to meet the technological needs of society. In many cases, the processing of a material is coupled with a phase transformation of some form. Consequently, the understanding of the phase transformation becomes a ciomisant factor in being able to control the processing of the material to achieve the desired or optimum set of properties. Thus, the study of phase transformations and/or phase characterization becomes a key to both our scientific understanding and advancement in current and emerging technologies. History has shown this to be the case for systems such as metallic alloys (e.g. Fe and Al alloys) and more recently for intermetallic, semiconductor, and oxide systems.

Most of the research focus of MATRIX has been on non-equilibrium states of materials and the transition from one state to another. In many cases it is a metastable state that is of interest and the kinetics involved with the changes. This transition forms the unifying element for MATRIX, the fact that these materials have a transition state/structure. This transition may manifest itself in many forms such as: chemical (ordering, clustering, etc.), defects (point, line, or interface), displacements (static or dynamic), or phonons (thermal; optical, etc.). Our group focuses their research effort ou the measurement of these transitions to allow us to better understand the physical phenomena under investigation. Understanding tie fa:tors which control the transformations (understanding the elements being modulated and the origin of the modulation) leads to new materials. Relating the factors to processing and process control (provides the basis for process selection and the identification of the critical parameters for control) leads to improved manufacturing. Correlating the modulated materials with physical properties can lead to a better theoretical understanding of the phenomena and to the synthesis of new materials. 


\section{DISCLATMER}

This report was prepared as an account of work sponsored by an agency of the United States Governmenc. Neither the United States Governmeat not any ageacy thereof, nor any of their employees, makes any warranty, express or implied, or essumes any legal liability or responsibility for the accuracy, completeress, or usefulness of any information, apparatus, product, or process disclosed, or represents that its use would not infringe privately owned rights. Reference herein to any specific commercial product, process, or service by trade name, trademark, manufacturex, or otherwise does not neeessarily constitute or imply its endorsement, recommendation, or favoring by the United States Government or any ageacy thereof. The views and opinions of authors expressed herein do not aecessarily state or reflect those of the United States Goverament or any ageacy thereof. 


\section{DISCLAIMER}

Portions of this document may be illegible in electronic image products. Images are produced from the best available original document. 
MATRIX Accomplishments.

The MATRIX beamline has succeeded in being a facility that enables researchers to conduct experiments with a high certainty of success. This was principally due to three factors: 1) the excellent design and management of the facility through the leadership of Steve Ehrlich and Jerry Liedl; 2) The rewarding and inspired environment at NSLS; and 3) the innovative research of the MATRIX participants. During this funding period over eighty papers using MATRIX beamline results were published and at least twelve graduate degrees were earned using results from the MATRIX beamline. The specific accomplishments are detailed in the next two sections.

\section{MATRXX Team Members:}

The MATRIX beamline has had a long list of team members, contributors and employees over the duration of beamline operation. Several of these members were involved in the inception of the beamline and have also made the greatest contribution to the publication record and research accomplishments. The following are the members of the beamline at the completion of this Department of Energy funding:

G. L. Liedl, Director, School of Materials Engineering, Purdue University (charter director - retired 1999) S. N. Ehrlich, Beam Line Manager (1986-1999), School of Materials Engineering, Purdue University (member since 1986)

John Schwanof, Beam Line Assistant, School of Materials Engineering, Purdue University (1993-2000)

R. Colella, Department of Physics, Purdue University (charter member)

H. Chen; Department of Materials Science and Engineering, University of Illinois at Urbana-Champaign (charter member)

H. Taub, Department of Physics, University of Missouri at Columbia (charter member)

P. E. Sokol, Department of Physics, Pennsylvania State University (member since 1996, director 2000-)

Keith Bowman, School of Materials Engineering, Purdue University (member since 1997, director 1999-2000)

L. J. Martinez-Miranda, Department of Physics, University of Maryland (member since 1997)

Cheng K. Saw, Hoechst Celanse (member since 1997)

Xiao-Qing Yang, Dept. of Applied Science, Brookhaven National Laboratory (member since 1997)

J. McBrecn, Dept. of Applied Science, Brookhaven National Laboratory (member since 1997).

Concurrent with the start of beamline operations directed from Penn State (and beyond this grant) the following Penn State researchers have joined the MATRIX community:

David Allara, Dept. of Chemistry

Karl Mueller, Dept. of Chemistry

David Vaughn, Dept. of Chemistry

Roy Willis, Dept. of Physics

Susan Brantley, Earth and Mineral Sciences

V. Goplan, Earth and Mineral Sciences

Peter Heany, Earth and Mineral Sciences

Earl Ryba, Earth and Mineral Sciences

Darrel Schlom, Earth and Mineral Sciences

Arthur Motta, Nuclear Engineering

Qiming Zhang, Materials Research Laboratory

Publication Record of MATRIX:

The MATRIX team has been very productive in turning the complex in situ experiments conducted on the beamline into published documentation of the research. The following provides a list of the publication record of the beamline for each year of operation under this grant:

$\underline{1994}$

1. Joanne Levine Parrill, Jerome B. Cohen, Yip-Wah Chung, "Ultra-High Vacuum Grazing Incidence Small angle Xray Scattering Camera for In Situ Surface Analysis," Advances in X-ray Analysis, 37, Edited by J. V. Gilfrich et al, 413-418 (19:4).

2. H. Renevier, S. B. Kan, J. F. Quintana, K. J. Thang, and J. B. Cohen, "Local Order in $\mathrm{Yba}_{2} \mathrm{Cu}_{3-y} \mathrm{CO}_{y} \mathrm{O}_{6+2 x}$ studied by anomalous diffuse X-ray scattering," J. Mater. Res., 9, No. 12, 3050-58 (1994). 
3. J. B. Cohen, "Long-Range Or' $1 \mathrm{~g}$ in the Early Stages of Precipitation-A Br? eview," Metallurgical and

- Materials Transactions A,.25A, 2564-68 (1994).

4. K. W. Herwig, J. C. Newton, and H. Taub, "Structure and Growth of Butane Films Adsorbed on Graphite," Phys. Rev. $B, 50,15287-15297$ (1994).

5. K. W. Herwig, B. Matthies, and H. Taub, "Preparation of Long-alkane Monolayers Adsorbed on Exfoliated Graphite for Neutron Diffraction. Studies," Neutron Scattering in Materials Science, edited by D. A. Neumann, T. P. Russell, and B. J. Wuensch, Mater. Res. Sol. Symp. Proc. 376 Pittsburgh, PA (1994).

6. V. Mahadev, M. R. Melloch, J. M. Woodall, N. Otsuka, and G. L. Liedl, "Effect of Dopants on Arsenic Precipitation in GaAs Deposited at Low Temperatures," Journal of Electronic Materials, 23, No. 9, pp. 1-13 (1994).

7. Huanbo Zhang, Hiroshi Sato and Gerald L. Liedl, "Possible Effect of Oxygen Content on the Under-doped Characteristics of the $\mathrm{La}_{2-\mathrm{x}} \mathrm{Sr}_{\mathrm{x}} \mathrm{CuOI}^{4+8}$ Compound," Physics C234, 185-89 (1994).

8. C. Venkatraman and G. L. Liedl, "Oriented Texture in $\mathrm{Yba}_{2} \mathrm{Cu}_{3} \mathrm{O}_{7 d}$ Films synthesized from Amorphous Precursors," J. of Electronic Materials, 2311 (1994).

$\underline{1995}$

4. X. B. Kan, H. Renevier, J. Quintana, J. L. Peng, and J. B. Cohen, "Anomalous X-ray diffuse scattering of shortrange order in $\mathrm{Nd}_{2-\mathrm{x}} \mathrm{Ce}_{\mathrm{x}} \mathrm{CuO}_{4-\mathrm{y}}$, J. Appl. Phys. 77 (1), pp. 34-40 (1995).

5. Naohisa Takesue, Mario Maglione and Haydn Chen, "X-ray thermal-diffuse-scattering study of soft modes in paraelectric $\mathrm{BaTiO}_{3}, 51$ (10), pp. 6696-6699 (1995).

6. S. Mansour, G. Liedl and R. Vest, "Microstructural Developments and dielectric Properties of Rapid Thermally Processed PZT Thin Films Derived by Metallo-organic Decomposition," J. Am. Ceram. Soc., 78 (6), pp. 1617-23 (1995).

7. R. Colella, "Multiple Bragg Scattering and the Phase Problem in X-ray diffraction. I Perfect Crystals," Comments Cond. Matt. Phys., 17, 175 (1995).

8. R. Colella, "Multiple Bragg Scattering and the Phase Problem in X-ray Diffraction, II Mosaic Crystals," Comments Cond. Matt. Phys., 17, 199 (1995).

9. R. Colella, "Enantiomorphism and Multiple Beam Diffraction. Revised." Acta Cryst. A51, 438 (1995).

\section{$\underline{1996}$}

1. J. C. Newton and H. Taub, "Neutron Diffriction Investigation of the S2 Monolayer Phase of Ethane Physisorbed on Graphite", Surf. Sci. 364, 273-278, (1996).

2. F. Y. Hansen, L. W. Bruch, and H. Taub, Molecular Dynamics Simulations of the Dynamical Excitations in Commensurate Submonolayer Films of Nitrogen Molecules on Graphite", Phys. Rev. B 54, 14077-14081 (1996).

3. S. Goldman, K. L. Kavanagh, H. H. Wieder, and S. N. Ehrlich, "Modulation-doped $\mathrm{In}_{0.53} \mathrm{Ga}_{0.47} \mathrm{As} / \mathrm{In}_{0.52} \mathrm{Al}_{0.48} \mathrm{As}$ Heterostructures Grown on GaAs Substrates Using Step-graded InxGal-XAs Buffers", J. Vac. Sci. Technol. B, July/Aug 1996

4. E. Smela and L. J. Martinez-Miranda, "Time Evolution of the Structure of Confined smC* Films", for submission to Molec. Cryst. Liq. Cryst.,1996.

5. R. S. Goldman, K. L. Kavanagh, H. H. Wieder, Y. M. Robbins, S. N. Ehrlich, R. M. Feenstra, "Correlation of buffer strain relaxation modes with transport properties of two-dimensional electron gases", J. Appl. Phys. 80 (1996) 684954. 
6. R. S. Goldman, K. L. Kavana, A. H. Wieder, and S. N. Ehrlich, "Modulation ped InGaAs/InAlAs Heterostructures Grown on GaAs Subștrates Using Step-Graded InGaAs Buffers", J. Vac. Sci. Tech. B, 14 (1996) 3035.

7. S. Williams, S. Maglic, C. Thomas, C.T. Lin, M.J. Wagoner, R.P.H. Chang, and J.B. Ketterson, "Growth and in situ characterization of YBa2Cu3Ox/LaA1O3 superlattices", Appl. Phys. Lett., 68, p. 1485, 1996.

8. K. Hongladarom, V. Ugaz, D. Cinader, W. R. Burghardt, J. P. Quintana, B. S. Hsiao, M. D.Dadmun, W. A. Hamilton and P. D. Butler, "Birefringence, X-ray Scattering and Neutron Scattering Measurements of Molecular Orientation in Sheared Liquid Crystalline Polymer Solutions," in press, Macromolecules 29 , 5346-5355, 1996.

9. P. Miller and K. J. Bowman, "The Relation of Contact and Toughness in Textured Silicon Nitride to Preferred Orientation," Proceedings of the Eleventh International Conference on Textures of Materials, [2] 1009-1014 (1996).

\section{$\underline{1997}$}

3. K. J. Bowman, M. Sandlin, R Roeder, D. Collins, N. W. Medendorp, C. Peterson, E. B. Slamovich, "Ceramics with Non-Uniform Microstructures and Anisotropic Properties, "Engr. Ceramics 96, Smolenice, Slovakia, Engr. Cer. '96: Higher Reliability through Processing, 285-300 (1997).

4. V. M. Ugaz, D. K. Cinader, Jr. and W. R. Burghardt, "Origins of Region I Shear Thinning in Model Lyotropic Liquid Crystalline Polymers, "Macromolecules 30, 1527-1530 (1997).

5. X. Yao, S. Ehrlich, G. Liedl, T. Hogan, C. Kannewurf, and J. M. Honig, "Electron Transport Phenomena In NiS $2-x$ Se Single Crystals, Mat. Res. Symp. Proc., 453, pp.291-303 (1997).

6. Kevin F. Peters, Yip-Wah Chung, and Jerome B. Cohen, Surface Melting on Small Particles, Appl. Phys. Lett. 71 (16), pp 2391-2393 (1997)

$\underline{1998}$

1. J. McBreen, S. Mukerjee and X. Q. Yang, In situ Synchrotron X-ray Studies of Battery and Fuel Cell Materials, Synchrotron Radiation News, 11, 18 (1998)

2. Y. Ein-Eli, S. H. Lu, M. A. Rzeznik, S. Mukerjee, X. Q. Yang, and J. McBreen, LiCuxMn $\mathrm{CH}_{2 \cdot \mathrm{O}} \mathrm{O}_{4}$ Spinels $(0.1<\mathrm{x}<$ 0.5): A New Class of Cathode Materials for Li Batteries, Journal of the Electrochemical Society, 145, 3383(1998).

3. Y. Ein-Eli, W. F. Howard, S. H. Lu, S. Mukerjee, J. McBreen, J. T. Vaughey, and M. M. Thackery, LiCuxMn2xO4 Spinels $(0.1<x<0.5)$ : A New Class of $5 \mathrm{~V}$ Cathode Materials for Li Batteries, Journal of the Electrochemical Society, 145, 1238(1998).

4. Y. Zhang, R. Colella, Q. Shen and S. W. Kycia, Dynamical Three-Beam Diffraction in a Quasicrystal, Actc Crystallographica A54, $411-415$ (1998).

5. Rachel Eisenhower, Roberto Colella and Benjamin Grushko, Multiple-Beam X-ray diffraction Studies of Decongonal Quasicrystals, Physical Review B, 57, (14) pp 8218-8222 (1998).

6. D. W. Brown, P. E. Sokol, and S. N. Ehrlich, "New Disorder Induced Phase Transitions of Classical Rare Gases in Porous Vycor Glass", Physical Review Letters 81 (5), 1019 (1998).

7. R. S. Goldman, K. L. Kavanagh, H. H. Wieder, S. N. Ehrlich, and R. M. Feenstra, "Effects of GaAs Substrate Misorientation on Strain Relaxation in InxGal-xAs-based Heterostructures", Journal of Applied Physics 83 (10), 5137 (1998).

8. R. S. Goldman, K. L. Kavanagh, H. H. Wieder, S. N. Ehrlich, and R. M. Feenstra, "Effects of GaAs Substrate Misorientation on Strain Relaxation in InxGal-xAs-based Heterustructures", Journal of Applied Physics 83 (10), 5137 (1998). 
9. S. Wan, W. Shelley and K. J. man, "Orientation and Anisotropy in Piezoé ic Ceramics," Int'l. Conference on Texture and Anisotropy of rolycrystals, Materials Science Forum 273-275, 581 1-586 (1998).

10. D. W. Brown, P. E. Sokol, S. N. Ehrlich, "New Disorder Induced Phase Transitions of Classical Rare Gases in Porous Vycor Glass", Phys. Rev. Lett. 81, 1019-1022 (1998).

11. V. M. Ugaz, D. K. Cinader, Jr. and W. R. Burghard, "X-Ray Scattering Investigation of Highly Concentrated Poly(benzyl glutamate) Solutions Under Shear Flow," J. Rheol. 42, 379-394 (1998).

12. W. R. Burghardt, "Molecular Orientation and Rheology in Sheared Lyotropic Liquid Crystalline Polymers," Invited Feature Article, Macromol. Chem. Phys. 199, 471-488 (1998).

13. Kevin F. Peters, Jerome B. Cohen, and Yip-Wah Chung, "Melting of Pb nanocrystals, Phys. Rev. B, 57, No.21, 13430-13438 (1998).

14. S. Wan and K. J. Bowman, "Thermal Depoling Effects on Anisotropy of Lead Zirconate Titanate Materials", J. Am. Ceram. Soc., 10, 2717-20 (1998).

15. Yufei Hu and L. J. Martinez-Miranda, "Evidence of the Presence of a Twist-Grain-Boundary Structure in Confined Hybrid Non-Chiral Smectic Liquid Crystal Films", Mat. Res. Symp. Proc., 543, 201-205 (1998).

16. A. W. Overhauser, Comment on "Is There an Electronic Topological Transition in Zinc under High Pressure?", Phys. Rev. Lett., 81, 4022 (1998).

17. D. Brown, P. Sokol, and S. Ehrlich, "New Disorder Induced Phase Transition of Classical Rare Gasses in Porous Vycor Glass", Bull. Amer. Phys. Soc. 43, 268 (1998).

18. S. Ehrlich, D. Brown, and P. Sokol, "Disordered Hexagonal Close Packed Structure of Confined Classical Rare Gases", Bull. Amer. Phys. Soc. 43, 268 (1998).

19. D. Silva, P. Sokol, J. Patel, and S. Ehrlich, "X-ray diffraction studies of the Smectic-A Phase of Liquid Crystals in Aligned Samples", Bull. Am. Phys. Soc. 43, 729 (1998).

20. Y. Ein-Eli, J. T. Vaughey, M. M. Thackeray, S. Mukerjee, X. Q. Yang, and J. McBreen, "LiCu $u_{0.5-x} \mathrm{Mn}_{1.5} \mathrm{O}_{4}$ Spinel electrodes, Superior High-potential Cathode Materials for Li Batteries. I. Electrochemical and Structural Studies", Journal of the Electrochemical Society, 146, 908 (1998).

1929

1. Pengcheng Dai, Z. Wu, T. Angot, S.-K. Wang, H. Taub, and S. N. Ehrlich, "Synchrotron X-ray Diffraction Study of the Structure and Growth of Xe Films Adsorbed on the Ag(111) Surface," Phys. Rev. B, 59, 15464-15479 (1999).

2. J. L. Norton, G. L. Liedl, and E.B. Slamovich, "Effect of oxygen partial fressure on texture development in $\mathrm{Pb}\left(\mathrm{Zr}_{0.60} \mathrm{Ti}_{0.40}\right) \mathrm{O}_{3}$ thin films processed from metallo-organic prescursurs", J. Mater. Res., in press (publication expected 12/99).

3. S. Wan, W. F. Shelley, II, and K. J. Bowman, "Mechanical Anisotropy of PZT Piezoelectric Ceramics, Ceramic Trans., Dielectric Ceramic Materials", Am. Ceram. Soc., 313-321 (1999).

4. S. Wan and K. J. Bowman, "Orientation Evolution of Textured Piezoelectric Ceramics under Electric Fields", ICOTOM 12, ed. J. Szpunar, NRC Press, Ottawa, Canada, August 10-13, 1453-59 (1999).

5. L. J. Martinez-Miranda, "Structural Studies of Partially Confined Smectic Liquid Crystal Films: Evidence for Double Confinement as a Function of Size and Depth", submitted to Phys. Rev. E, 1999.

6. Y. Li, L. J. Martinez-Miranda, G. M. Chow, and L. K. Kurihara, "A deptl profile study of the structure and strain distribution in chemically grown Cu films on AlN", NanoStructured Materials, 12, 653-656 (1999).

7. L. J. Martinez-Miranda, Y. Hu and T. K. Misra, "Thickness dependence of the glass-liquid crystal buried interface structure", Molec. Cryst., Liq. Cryst., 329, 733 (1999). 
8. L. J. Martinez-Miranda, Y. Shi and S. Kumar, "Time Evolution of the Structure of Sm-C* Films", Molec. Cryst. Liq. Cryst., 326, $41-48$ (1999).

9. L. J. Martinez-Miranda, Y. Li, V. Nagarajan, S. Aggarwal and R. Ramesh, "Depth Profile Study of Ferroelectric Lead-Zirconium-Titanate (PZT) Films on Deposited on Strontium Titanate", to be submitted to JAP, 1999.

10. M. Petit, N. Angarajan, S. Aggarwal, R. Ramesh and L. J. Martinez-Miranda, "Strain Study of Ferroelectric LeadZirconium-Titanate (PZT) Deposited on Lanthanum Aluminate Oxide (LAO)", submitted to Integrated Ferroelectrics, 1999.

11. N. Takesue, Y. Fujii, M. Ichihara, and H. Chen, "Self-Accommodation of Ionic Size-Effect Atomic Displacements in Antiferroelectric Order in Relaxor Lead Scandium Niobate", Phys. Rev. Lett., 82, 3709-3712 (1999).

12. A. W. Overhauser, G. Lacueva, A.S. Bakulin, "Diffraction Satellites in Indium Caused by Thermal-Diffuse Scattering", Phys. Rev. B, 59, 12444 (1999).

13. A. W. Overhauser, "Temperature Dependence of the Josephson Current", Phys. Rev. Lett., 83, 180 (1999).

14. C.-J. Yu, A. G. Richter, A. Datta, M. K. Durbin and P. Dutta, "Observation of molecular layering in thin liquid films using X-ray reflectivity", Phys. Rev. Lett., 82, 2326 (1999).

15. Terrence Jach, Y. Zhang, R. Colella, M. de Boissieu, M. Boudard, A. I. Goldman, T. A. Lograsso, D. W. Delaney, and S. Kycia, "Dynamical Diffraction and X-ray Standing Waves from Atomic Planes Normal to a Twofold Symmetry Axis of the Quasicrystal AlPdMn", Phys. Rev. Lett., 82, 2904-7 (1999).

16. M. Kopecky and R. Colella, "Exploring Reciprocal Space of a Quasicrystal by Means of an Imaging Plate". J. Appl. Cryst., 32, 442-51 (1999).

17. T. E. Burns, J. R. Dennison and S. N. Ehrlich, "Synchrotron X-ray Diffraction of Layering Transitions of Multilayer Nitrogen Physisorbed on Graphite", Langmuir, 15, 1423-1428 (1999).

18. X. Q. Yang, X. Sun, S. J. Lee, S. Mukerjee, J. McBreen, M. L. Daroux, and X. K. Xing, "In Situ Synchrotron X-ray Diffraction Studies of the Phase transitions in $\mathrm{Li}_{x} \mathrm{Mn}_{2} \mathrm{O}_{4}$ Cathode Materials", Electrochemical and Solid State Letters, 2, 157 (1999).

19. X. Q. Yang, X. Sun, and J. McBreen, "New Findings on the Phase Transitions in $\mathrm{Li}_{1-x} \mathrm{NiO}_{2}$ and $\mathrm{Li}_{1-x} \mathrm{CoO}_{2}$ : In Situ Synchrotron X-ray Diffraction Studies", Electrochemistry Communications, 1, 227 (1999).

20. Chungjong Yu, Andrew G. Richter, Alokmay Datta, Mary K. Durbin and Pulak Dutta, "Observation of molecular layering in thin liquid films using X-ray reflectivity", Advanced Photon Source Research, 2, 7-11 (1999).

$\underline{2000}$

1. X.Q. Yang, X. Sun, J. McBreen, New Phase and Phase Transitions Observed in Li (1-x)CoO_2 During Charge: In Situ Synchrotron X-ray Diffractions Studies, Electrochemistry Comm., 2, 100, 2000.

2. X.Q. Yang, X. Sun, M. Balasubramanian, J. McBreen, Y. Xia, T. Sakai, M. Yoshio, Effects of Oxygen Vacancy Population on Temperature Dependent Structural Changes in Li_(1+y)Mn_(2-y)O_4 Type Cathode Materials, Electrochemical and Solid State Lett. (submitted), 2000.

3. X.Q. Yang, X. Sun, M. Balasubramanian, J. McBreen, Relationship Between Cycling Performance and Structural Phase Transitions of Li_(1+y)Mn_(2-y)O_4 Cathode Materials Studied by Synchrotron X-ray Diffraction, 10th Int. Meeting on Lithium Batteries, Como, Italy, 2000 In Press.

4. WuWu, S. N. Ehrlich, B. Matthies, K. W. Herwig, Pengcheng Dai, U. G. Volkmann, r. Y. Hansen, and H. Taub, Quasiepitaxial Growth mode of n-Alkane Films Adsorbed on a Solid Substrate, Phys. Rev. Letters, 2000 Submitted.

5. R. Colella, G. Cappello, A. Dechelette, F. Schmithusen, S. Decossas, J. Chevrier, F. Comin, V. Formoso, D. de Boissieu, T. Jach, T. Lograsso, C. Jenks, D. Delaney,Bulk and Surface Evidences for the Long Range Spatial 


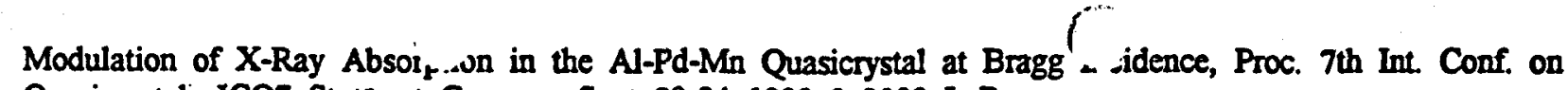

- Quasicrystals, ICQ7, Stuttgart, Germany, Sept. 20-24, 1999, 0, 2000, In Press.

5. Y. Xia, T. Sakai, T. Fujieda, X.Q. Yang, X. Sun, J. McBreen, M. Yoshio,Co-relating Capacity-Fading and Structural Changes in Li_(1+y)Mn_(2-y)O_(4-delta) Spinels Cathode Materials: A Systematic Study on the Effects of LiMn Ratio and Oxygen Deficiency,J. of Electrochemical Soc., 0, 2000, Submitted.

6. X. Sun, Q. Yang, J. McBreen, Y. Gao, M.Y. Yakovleva, X.J. Xing, M.L. Daroux, Studies on Relationship Between Structure of Over-charge State and Thermal Stability for LiNiO_2 Based Cathode Material, Proc. of Symp. on Lithium Battery in the 196th Meeting of Electrochemical Society, 0, 2000, In Press.

7. X.Q. Yang, X. Sun, J. McBreen, New Finding on the Phase Transitions in LiCoO_2 and LiNiO_2 Cathode Materials During Cycling: In-Situ Synchrotron X-Ray Diffraction Studies, Proc. of Symp. on Lithium Battery in the 196th Meeting of Electrochemical Society, 0, 2000, In Press.

10. X.Q. Yang, X. Sun, H.S. Lee, J. McBreen, Electrochemical and Thermal Stability Studies of Composite Electrolytes Containing Boron-based Anion Receptors for Lithium Batteries, Proc. of Symp. on Lithium Battery in the 196th Meeting of Electrochemical Society, 0, 2000, In Press.

11. X. Sun, X.Q. Yang, J. McBreen, Y. Gao, M.V. Yakovleva, X.K. Xing, M.L. Daroux, New Phase and Phase Transitions Observed in Over-Charged States of LiCoO_2-based Cathode Materials, J. of Power Source (accepted), $0,2000$.

12. X.Q. Yang, X. Sun, M. Balasubramanian, J. McBreen,Relationship Between Cycling Performance and Structural Phase Transitions of Li_(1+y)Mn_(2-y)O_4 Cathode Materials Studied by Synchrotron X-ray Diffraction, J. of Power Source (accepted), 0, 2000.

13. X.Q. Yang, X. Sun, J. McBreen,Structural Changes and Thermal Stability: In Situ X-ray Diffraction Studies of a New Cathode Material LiMg_(0.125)Ti_(0.125)Ni_(0.75)O_2, Electrochemistry Comm. (accepted), 0, 2000.

14. C.-J. Yu, A. G. Richter, J. Kmetko, A. Datta and P. Dutta,X-ray diffraction evidence of ordering in a normal liquid near the solid-liquid interface, Europhys. Lett., 50, 487, 2000.

15. N. Takesue, H. Kubo, H. Chen,Lattice Dynamics Study on Paraelectric Barium Titanate Based Upon a Modified Rigid-Shell Model, J. Ferroelectrics, in press, 0, 2000.

16. C.-J. Yu, A. G. Richter, A. Datta, M. K. Durbin and P. Dutta,Molecular layering in a liquid on a solid substrate: an X-ray reflectivity study, Physica B 283, 27, 2000.

17. C.-J. Yu, A. G. Richter, A. Datta, M. K. Durbin and P. Dutta,Observation of molecular layering in thin liquid films using X-ray reflectivity, Phys. Rev. Lett. 82, 2326, 1999.

18. R. Colella, T. Jach, Y. Zhang, M. de Boissieu, M. Boudard, A.I. Goldman, T.A. Goldman, T.A. Lograsso, D.W. Delaney, S.W. Kycia,Dynamical Diffraction and X-ray Standing Waves from Atomic Planes NL-mal to a 2-fold Symmetry Axis of the Quasicrystal Al-Pd-Mn, Phys. Rev. Lett., 82, 2904, 1999.

19. R. Colella and M. Kopecky,Exploring Reciprocal Space of a Quasicrystal by Means of an Imaging Plate, J. App. Crystallography, 32, 442, 1999.

20. T. E. Burns, J. R. Dennison, Utah State University; and S. N. Ehrlich, Purdue University,Synchrotron X-ray Diffraction of Layering Transitions of Multilayer Nitrogen Physisorbed on Graphite, Langmuir 15, 1423, 1999.

20. Pengcheng Dai, Z. Wu, T. Angot, S.-K. Wang, H. Taub, and S. N. Ehrlich, Synchrotron X-ray Diffraction Study of the Structure and Growth of Xe Films Adsorbed on the Ag(111) Surface, Phys. Rev. B, 59,15464,1999. 
$\therefore \quad$ MATRX Graduate Student Pri cetion:

In addition to production of research papers, the MATRDX facility has introduced many graduate students to the

rewarding challenges of offsite research at a major research facility. Preparing and carrying out remote research can be one of the most rewarding accomplishments in the career of many graduate students. The following is a list of graduate student MATRIX participants that completed their degrees during the period of this funding (grouped by their advisor):

K. J. Bowman, Purdue University, School of Materials Engineering

- Michael Sandlin, "Seeded Texture Development in AlN-SiC Platelet Composites", Ph. D. 1995

Hereaus, Phoenix, Arizona

- David Collins, "Pyrolysis of a Zirconium Alkoxide to Produce Zirconia Fibers," M. S. 1994, Intel Corp., Portland, OR

- Shan Wan, "Texture and Anisotropy in Piezoelectrics," Ph. D. 2000, Post-Doctoral Researcher, Georgia Tech, Atlanta, GA.

- Xiongqiong Tu, "Field-Induced Strain in Relaxor Ferroelectrics," M. S. 2000, Computer Consultant, Silicon Valley, CA.

R. Colella, Purdue University, Dept. of Physics

- Rachel Eisenhower, "Multiple Bragg Scattering in Decagonal Quasicrystals", Ph. D., May 1996. Postdoctoral Research Associate at the National Synchrotron Light Source, Brookhaven National Laboratory.

- Yi Zhang, "X-Ray Diffraction Studies of Al-Pd-Mn Quasictystal. Structural and Thermal Properties". PhD., December 1997. Staff Scientist at Qualcomm Inc., San Diego, California.

G. L. Liedl, Purdue University, School of Materials Engineering

- Vadali Mahadev, "Structural Characterization of Pseudo-Insulators for Gallium Arsenide Devices", Ph. D. May

- I995; Postdoctoral Research Associate at U. of Arizona

- Jarrod Norton, "Orientation Development in PZT-MOD Thin Films: Effect of Oxygen Partial Pressure", MS

$\because \quad 1996$

- Jarrod Norton, Investigation of an X-Ray Diffraction-Based Techrique for Measurement of Electrostrictive Strains," Ph.D., 1999.

H. Chen, University of Illinois, Champaign-Urbana, Dept. of Materials Science and Engineering

- Naohisa Takesue, "Thermal Diffuse Scattering and Inpurity Effect on the Para-To-Ferroelectric Transitions of $\mathrm{PbTiO}_{3}$ and $\mathrm{BaTiO}_{3}{ }^{\prime \prime}, \mathrm{Ph} . \mathrm{D}$., October 1996. Institute of Solid State Physics, University of Tokyo, Japan.

K̇aren L. Kavanagh and Harry H. Wieder, University of Califormia-San Diego, Dept. of Physics

- Rachel Goldman, "Structural and Electronic Properties of Lattice-Matched Compound Semiconductor Heterostructures", Ph.D. Sept. 1995, Assistant Professor, Dept. of Materials Science \& Engineering, University of Michigan

P. Sokol, Penn, State Univerisity, Dept. of Physics

- D. Brown - "X-ray scattering Studies of Argon and Krypton in Solgel Glasses", Currently Staff Member,

- Materials Science Division, Los Alamos National Lab.

$\because \quad$ H. Taub, University of Missouri- Columbia, Dept. of Physics

$\because \quad$ Zhongming Wu, "Diffraction Studies of the Structure and Growth of Films Adsorbed on the Ag(111) Surface,

- Ph.D., December 1997, Postdoctoral Research Associate, Departments of Physics and Materials Engineering, University of Illinois, Urbana-Champaign. 